\title{
RESEARCH REVIEW
}

\section{The Story of Managed Ventricular Pacing}

\author{
DAVID A. CASAVANT, $\mathrm{MS}^{1}$ and PAUL BELK, $\mathrm{PhD}^{2}$
}

\author{
'Unaffiliated \\ ${ }^{2}$ Boston Scientific, Natick, MA, USA
}

\begin{abstract}
A significant milestone in cardiac pacing occurred approximately two decades ago, when the primary operating mode was reimagined to more closely mimic normal top-down cardiac activation. When introduced, Managed Ventricular Pacing (MVPтм; Medtronic, Minneapolis, MN, USA) was an unprecedented dual-chamber mode as it preferentially paced the right atrium in the AAI/R mode and simultaneously protected against transient heart block, albeit only in the instance of dropped ventricular beats. At the time, dual-chamber DDD/R with atrial-based timing and programmable atrioventricular delay was state of the art. MVPTM "unlocked" conventional dual-chamber pacing by not consistently requiring a 1:1 atrioventricular relationship during its primary operating mode (ie, $A A I / R+$ ). Ultimately, $M V P^{\mathrm{TM}}$ emerged as a primitive means to promote His-Purkinje activation, and it is not a coincidence that its roots can be traced back to first-in-man permanent His-bundle pacing.
\end{abstract}

KEYWORDS. Cardiac pacing, Managed Ventricular Pacing, mode switching.

\author{
ISSN 2156-3977 (print) \\ ISSN 2156-3993 (online) \\ CC BY 4.0 license
}

C 2021 Innovations in Cardiac Rhythm Management

\section{Introduction}

"Don't be trapped by dogma-which is living with the results of other people's thinking. Don't let the noise of others' opinions drown out your inner voice. And, most importantly, have the courage to follow your heart and intuition." - Steve Jobs

Managed Ventricular Pacing (MVPTM; Medtronic, Inc., Minneapolis, MN, USA) was conceived as a permanent pacing modality in 1999, nearly three decades after an atrial lead was added to permanent pacing and dual-chamber pacemakers were commercialized. ${ }^{1}$ At the time, pacemakers were indicated in more than two-thirds of paced patients to correct symptoms resulting from abnormally slow origination of impulses in the sinoatrial node. Yet, as pacemakers were developed from the bottom up, starting with a VOO mode, they incrementally evolved to pace in a dual-chamber fashion such that every cardiac cycle ended with a ventricular sensed or paced event. Atrioventricular (AV) hysteresis, introduced in 1995, periodically extended AV delay for one beat and

Mr. Casavant was a Medtronic employee from 1988 to 2013. Dr. Belk was a Medtronic employee from 1998 to 2012.

Manuscript received November 10, 2020. Final version accepted December 28, 2020.

Address correspondence to: David A. Casavant, MS, 25 Puritan Road, Reading, MA 01867, USA. Email: dcasavant@yahoo.com. represented the first attempt to encourage intrinsic conduction. More sophisticated AV search hysteresis algorithms became available in 1999 and strived to discover intrinsic conduction over a series of beats. However, as aggressive as these algorithms were, they were limited by the programming confines of DDD/R pacing, including, most notably, the restrictions imposed to avoid 2:1 pacemaker block. MVP ${ }^{\mathrm{TM}}$ was revolutionary as it differed from all other dual-chamber modes and relaxed the requirement that all atrial events be followed by a ventricular event. In doing so, ventricular pacing was practically eliminated in all patients except those with persistent complete heart block. ${ }^{2}$

The approval of MVP ${ }^{\text {TM }}$ by the United States Food and Drug Administration in August 2004 did not require a large, prospective randomized trial. Instead, it was approved following two relatively small temporary software download trials involving a total of 211 patients (30 patients using the Gem III DR system and 181 using the Marquis DR system, respectively; both Medtronic). Both trials proved MVPTM to be safe and highly effective in reducing right ventricular (RV) pacing, with no clinical endpoints. The commercial release was bolstered by emerging and compelling evidence showing the harmful effects of RV overpacing. The most compelling trial findings came from the Dual Chamber and VVI Implantable 
Defibrillator (DAVID) trial $^{3}$ and the Mode Selection Trial (MOST) and its substudy ${ }^{4}$ published between 2002 and 2003. In combination, these trials provided incontrovertible evidence that ventricular overpacing contributed to heart failure (HF) and atrial fibrillation (AF). Another important contemporaneous realization came from evidence that iatrogenic left bundle branch block created by RV pacing activation was equally harmful in patients with congestive HF without left bundle branch block. ${ }^{5}$ As such, results from early cardiac resynchronization therapy trials further contributed to the early adoption of MVPтм. 6,7

\section{The MVPTM story}

The true origin of MVPTM can be traced back to 1995, when its predominant AAI+ operation was first described by David Casavant, a Boston-based field clinical engineer, as a means to safely facilitate atrial capture threshold determination (Figure 1) ${ }^{8}$ Prior to pacemaker systems having a real-time, multichannel electrocardiogram (ECG) and event marker display, the assessment of atrial capture during attended follow-up was difficult and virtually impossible in patients with sinus tachycardia or frequent premature atrial contractions and complete heart block (Figure 2A). An innovation known as "facilitated atrial pacing threshold testing" (FAPTT) emerged as a means to more easily perform the atrial threshold test by way of 2:1 AV pacing. Doing so thereby extends the isoelectric time and allowed visualization of atrial capture on alternating beats (Figure 2B) ${ }^{8}$ Notably, the invention maintained atrial-only pacing in the event of intrinsic conduction and thereby allowed for atrial capture inference during sustained overdrive atrial pacing (Figure 2C).

The timeline and motivations for the development of MVP $^{\mathrm{TM}}$, highlighting the controversies and uncertainties that surrounded the conception of a feature that continues to be considered standard of care, are described henceforth.

A

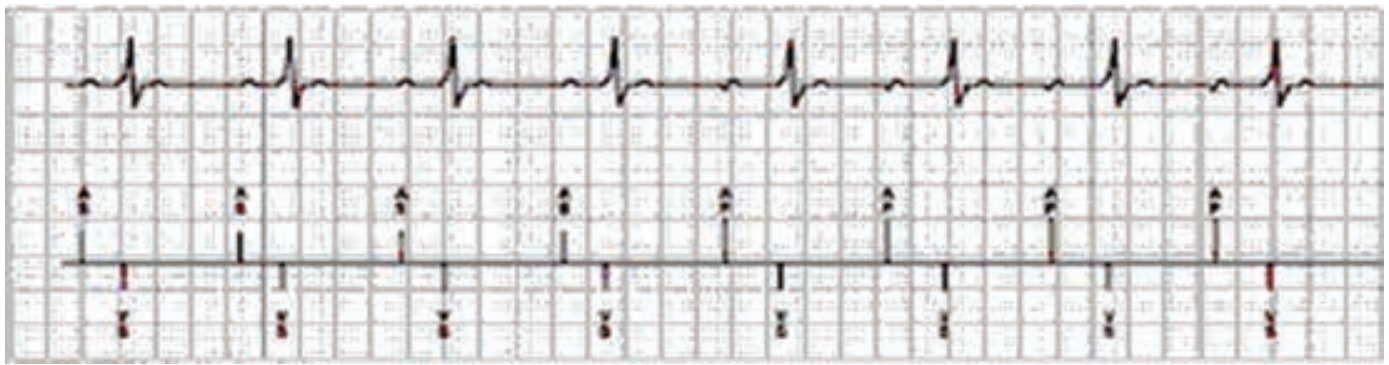

B

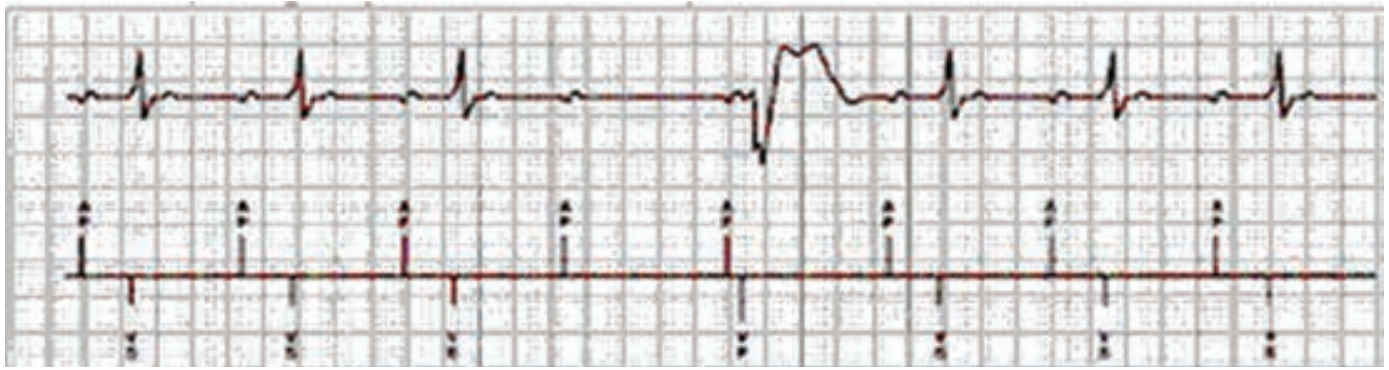

C

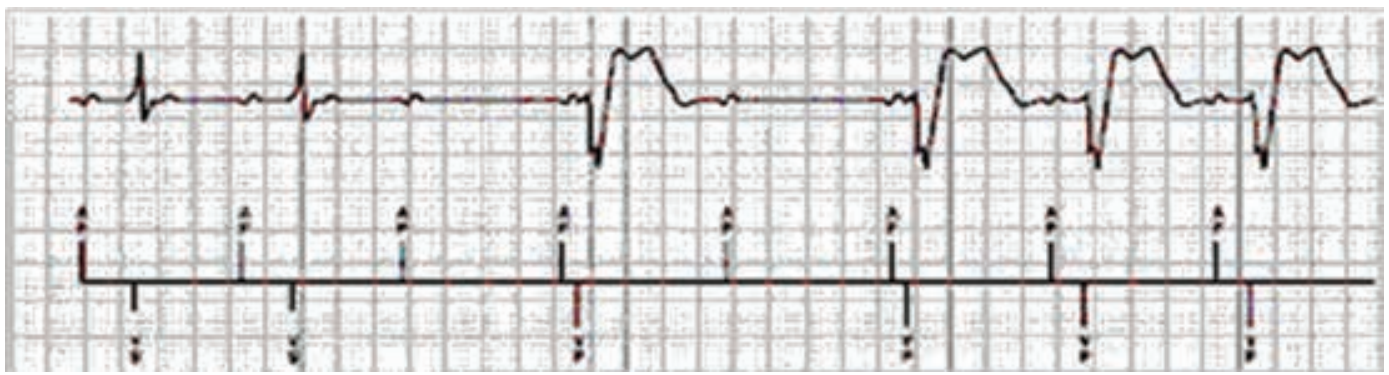

Figure 1: A: ECG and Marker ChannelTM captured in the AAI/R+ mode, MVPTM's predominant operating mode in patients with intact conduction. B: Example showing issuance of a backup ventricular pace following a singular nonconducted atrial event. C: Conversion to a temporary DDD/R mode in the event of high-degree heart block (ie, two of four intervals without a ventricular sense). Not shown is the AAI/R+ restoration method, which involves dropping a ventricular pace periodically and which is deemed successful if a ventricular sense occurs prior to the next atrial event. 


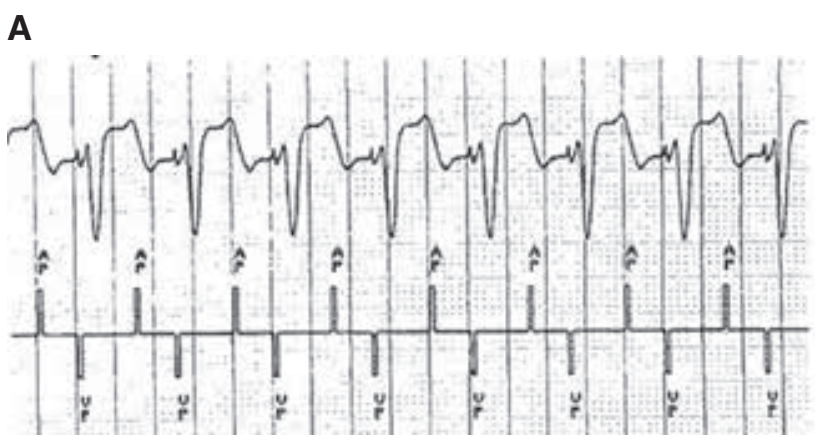

B

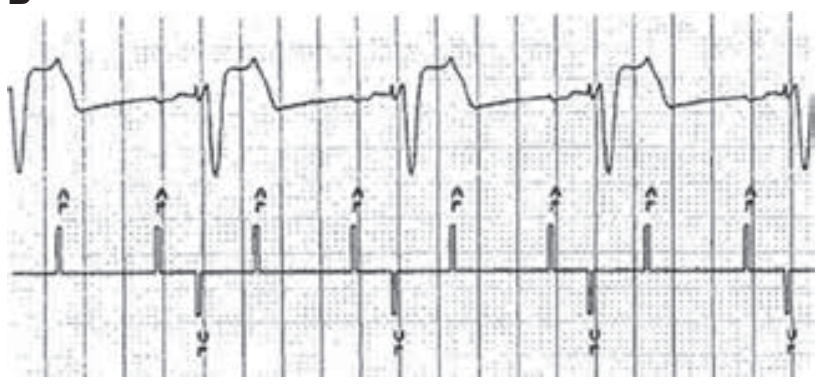

C

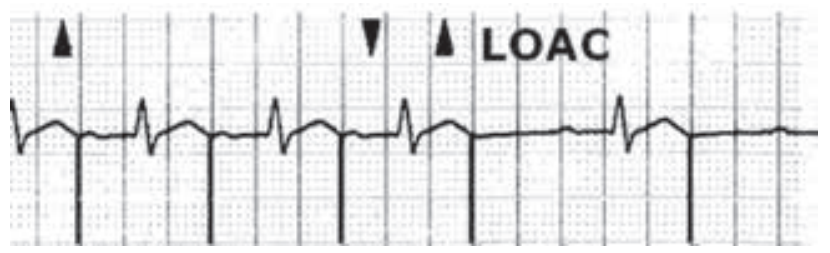

Figure 2: A: ECG/marker strip taken during 1:1 AV pacing at a rate of $120 \mathrm{ppm}$. Atrial capture verification was complicated by an overlap of atrial pacing and the terminal end of the ventricular paced complex. B: ECG/marker strip taken during $2: 1 \mathrm{AV}$ pacing at a rate of $120 \mathrm{ppm}$. Note that, by liberating isoelectric time, atrial capture assessment on alternating intervals is visually unhampered. C: Sustained ADI pacing in the event of 1:1 AV conduction. Loss of atrial capture (LOAC) is indicated by an abrupt and sustained fallback in heart rate with the appearance of native $p$-waves on the ECG.

\section{Conceptualization}

In the case of MVPTM, a common falsehood is that the development of MVPTM was a response to multicenter trials-most notably, the DAVID trial-which were designed to confirm the general understanding that excess ventricular pacing was harmful. When MVPтм was initially developed in 1999 and 2000, the idea of harm from ventricular pacing was a very small minority opinion. In fact, the original purpose of the DAVID trial was to establish the superiority of dual-chamber pacing, and the results of the DAVID trial (which was terminated early) represented only the beginning of a reevaluation of that idea.

$\mathrm{MVP}^{\mathrm{TM}}$ has been recognized as a disruptive innovation that was introduced well before its time and continues to be prescribed as a mainline treatment for patients with sinus node dysfunction and/or paroxysmal heart block.
At the time of its conception in 1999, the most significant clinical evidence that AAI was superior to DDD was from a small (ie, 177 patients), randomized, prospective (DANPACE I) trial performed in Denmark, which showed a significantly lower incidence of AF in patients paced with the AAI mode. ${ }^{9}$ Although AAI-mode pacing was prescribed routinely in some European countries, atrial-only pacing never obtained a foothold in the United States, with few American device implanters willing to risk the possibility of frank syncope in a pacemaker patient. At the time that evidence of AAI pacing's superiority in sick sinus syndrome patients began to mount, insertion of an RV pacing lead had already become an established practice. In a country having a robust health care system and a degree of litigiousness, single-lead ventricular pacing simply evolved directly to dual-lead AV pacing systems and, in the United States, little consideration was given to atrial-only pacing. In fact, AAI pacing was declared extinct in $2001 .^{10}$ The best option for sick sinus syndrome patients at the time was programming DDD/R or DDI/R with a long AV (eg, $350 \mathrm{~ms}$ ) delay, but static, long AV delays introduced the potential for retrograde conduction and resultant arrhythmias, including pacemaker-mediated tachycardia and repetitive non-reentrant ventriculoatrial synchrony.

MVPTM $^{\text {TM }}$ wully described before the plan for the DAVID trial was publicly announced ${ }^{11}$ and before the MOST substudy results were published. ${ }^{4}$ Interestingly, the MOST and DAVID trials hypothesized that dual-chamber DDD pacing, then considered the universal pacing mode, was likely to prove superior. Ultimately, the MOST trial showed that DDD pacing was equivocal to VVIR with respect to the combined endpoint of death or nonfatal stroke and confirmed that the degree of ventricular pacing in both the DDD and VVIR modes contributed to increased HF hospitalizations and AF, while the DAVID trial showed that DDD pacing increased the combined endpoint of death or HF hospitalization relative to backup VVVI pacing in patients with implantable cardioverterdefibrillators (ICDs) having compromised left ventricular function. It was ultimately the combined results from DANPACE I, the MOST substudy, and DAVID, together with the coincidental realization of the harmful effects of dyssynchronous ventricular activation gained from early cardiac resynchronization therapy trials, ${ }^{6,7,12-16}$ that cinched the destiny of MVPTM.

Although dual-chamber pacing had become widely accepted as the "physiologic" or "universal" pacing modality in the mid- to late 1990s, the existence of excessive ventricular pacing was troubling to Casavant and Paul Belk, a Medtronic field scientist stationed at Boston's Beth Israel Hospital. Casavant had worked extensively with Dr. Pramod Deshmukh, widely recognized as the electrophysiologist who pioneered permanent His-bundle pacing. In the early 1990s, Dr. Deshmukh had realized that pacemaker implantation in patients with compromised left ventricular function often seemed to exacerbate their $\mathrm{HF}$ and accelerate mortality. More importantly, though, he understood why. In 1968, researchers had shown that 
those ventricles that were activated normally via temporary His bundle pacing functioned better. ${ }^{17}$ As the collaborator and coauthor of the landmark publication describing first-in-man permanent His-bundle pacing, Casavant learned the paramount importance of preserving normal activation in pacemaker-indicated patients with failing hearts. ${ }^{18}$ Published studies suggesting adverse consequences from the use of conventional DDD/R pacemakers already existed but were largely ignored. ${ }^{19-23}$ Most notably, a publication in 1993 from a large single-center study involving 557 patients hospitalized for HF showed that the risk of non-sudden cardiac death at one year was $48 \%$ higher in patients with pacemakers. ${ }^{24}$ Belk had done his $\mathrm{PhD}$ work in developing a finite element model of ventricular arrhythmias and had concluded that abnormal ventricular activation increased ventricular tachyarrhythmia susceptibility in ICD-indicated patients. Under the guidance of Dr. Mark E. Josephson, he designed a simple protocol in patients being evaluated for ICDs and showed that ventricular tachycardia (VT) was more readily induced when premature ventricular stimuli (ie, S2, $\mathrm{S} 3, \mathrm{~S} 4)$ were delivered in the wake of a ventricular paced (S1) drive train than when premature ventricular stimuli were delivered at the same coupling intervals following a narrow QRS drive train produced by atrial pacing. ${ }^{25}$

MVP $^{\mathrm{TM}}$ was conceived in a clinical environment in Boston without substantial input from the vast array of Medtronic in-house engineers, scientists, marketing, and product planners. The widespread realization that ventricular pacing was possibly not benign began following a presentation of the MOST results as a late-breaking clinical trial at the North American Pacing and Electrophysiology Society Meeting in 2001. Thereafter, it became a higher priority for pacemaker practitioners to avoid ventricular pacing. Programming long AV delays within the constraints of DDD/R pacing, mainly to avoid pacemaker 2:1 block at elevated sinus rates, however, was often a difficult task. Although pacemakers with AV search hysteresis DDD/R-mode algorithms did prove to be quite effective in reducing ventricular pacing in pacemaker recipients, ${ }^{26-28}$ they had not yet been implemented or even tested on a dual-chamber ICD platform. In fact, initial DDD ICDs introduced in the United States in 1998 (Ventak AVTM; Guidant, Indianapolis, IN, USA), 1999 (Gem DR ${ }^{\mathrm{TM}}$; Medtronic), and 2000 (Photon DR; St. Jude Medical, St. Paul, MN, USA), respectively, did not incorporate $\mathrm{AV}$ search algorithms.

The most important influence on the "AV delay-less" design of MVPTM was that it provided a means to overcome a mandate imposed by Medtronic's dual-chamber ICD designers that the VP-AP interval "fit" within the VT detection zone at all times so as to not interfere with VT detection due to same-chamber and cross-chamber post-pace blanking periods. Such a scenario could easily be demonstrated on a simulator (Figure 3). At the time, most electrophysiologists and industry experts maintained that the primary function of ICDs was to protect patients from malignant ventricular tachyarrhythmias and accepted that some degree of ventricular overpacing was acceptable.

\section{Development efforts}

To fully define MVPTM as a permanent pacing modality, the following enhancements were added to the FAPTT algorithm: (1) an AV delay of $80 \mathrm{~ms}$ following a nonconducted atrial event, which was chosen for being the shortest AV delay known to be asymptomatic during the

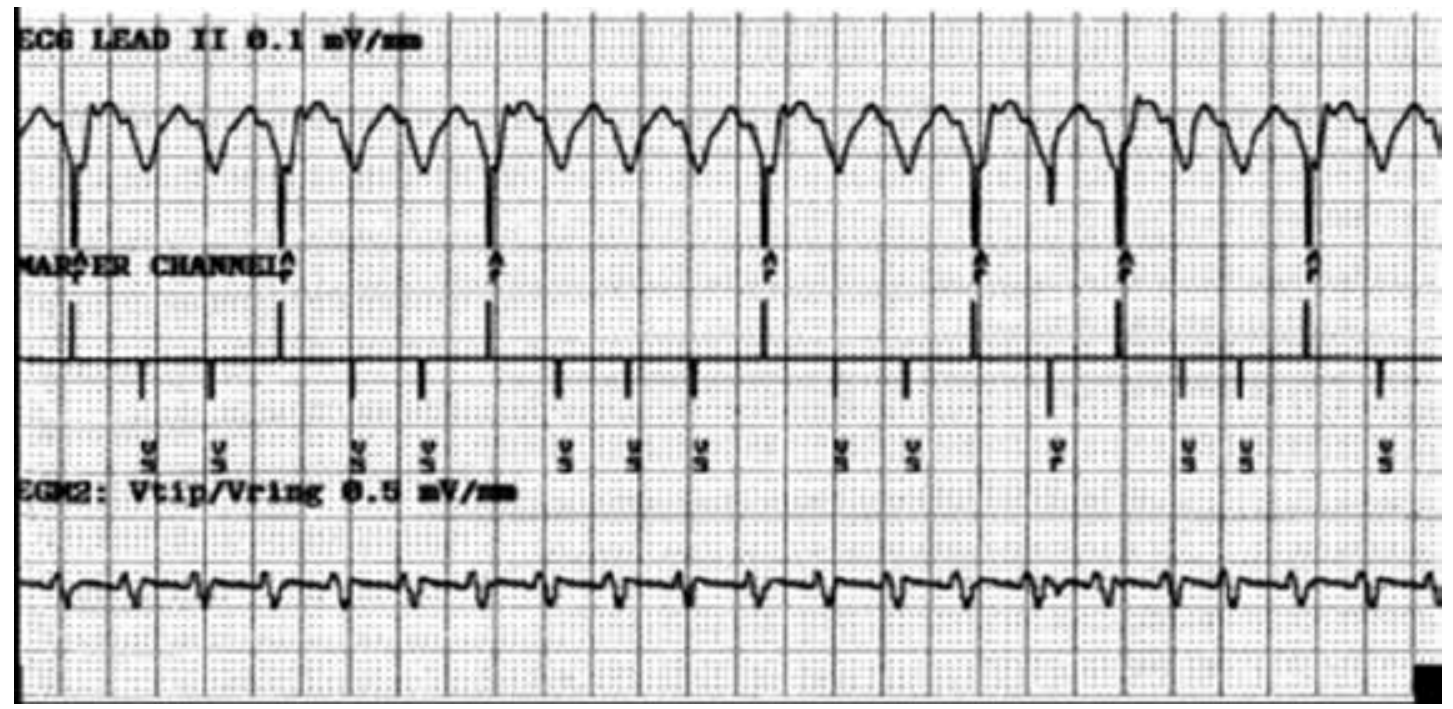

Figure 3: Simulated failure to detect rapid VT due to long AV delay programming and interference from post-Ap and post-Vp ventricular blanking periods during sensor-driven pacing at $100 \mathrm{bpm}$ and during VT at a rate of $200 \mathrm{bpm}$. Programmed DDDR, lower rate $(\mathrm{LR})=60 \mathrm{bpm}$, upper sensor rate $(\mathrm{USR})=130 \mathrm{bpm}$, paced $\mathrm{AV}(\mathrm{PAV})=280 \mathrm{~ms}$, tachycardia detection interval $($ TDI $)=$ $280 \mathrm{~ms}$, and fibrillation detection interval (FDI) = $320 \mathrm{~ms}$ (VS markers are not denoted as TS as the above could only be simulated). UR: upper rate. 


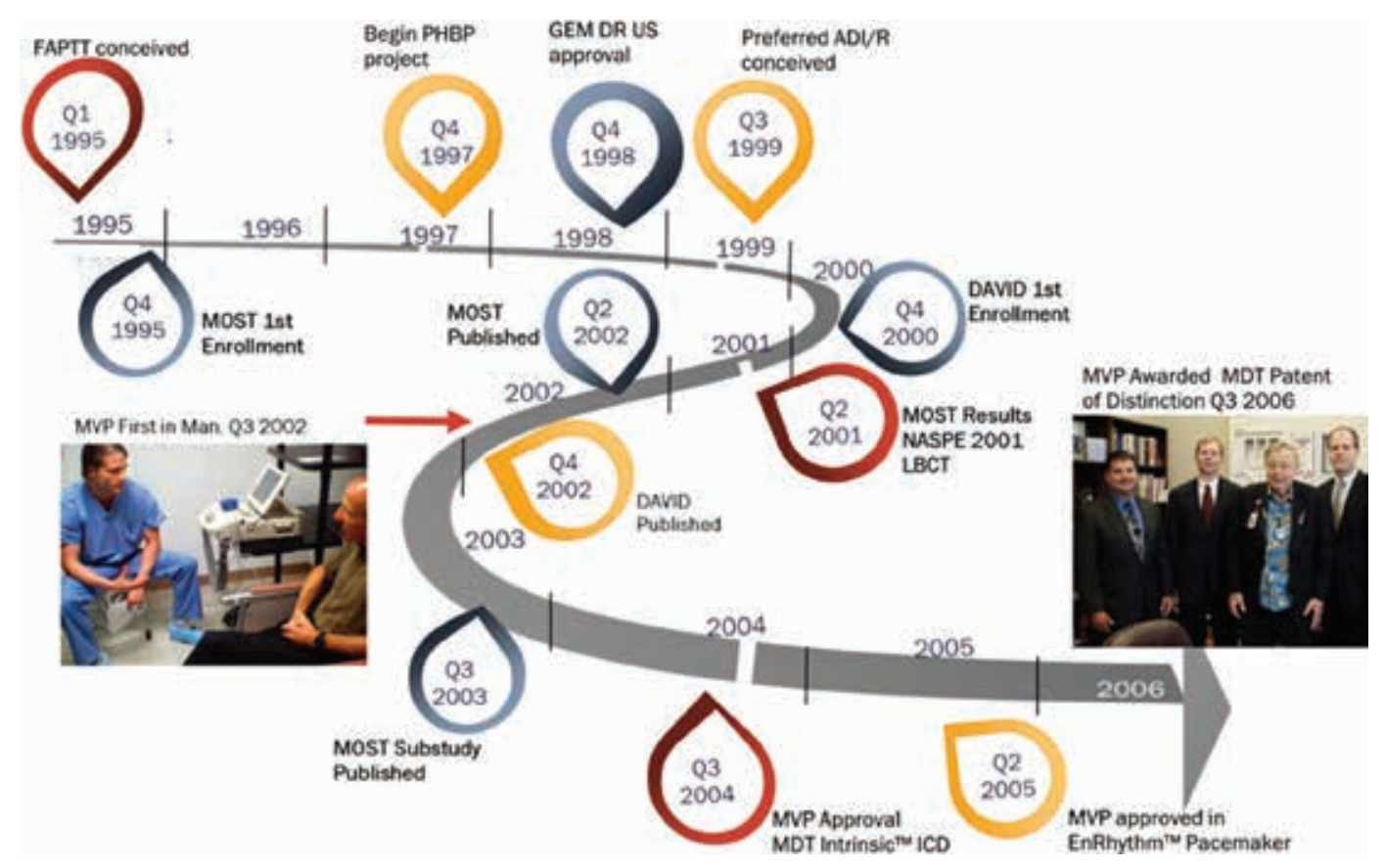

Figure 4: Timeline showing the evolution of MVPTM from preconception to final release. FAPTT refers to a facilitated atrial threshold test. Preferred ADI/R was the original name for MVPTM. On the left, Dr. Michael O. Sweeney is pictured with the first MVPTM patient during the Gem III DR download study. On the right, David Casavant, Paul Belk, Medtronic founder Earl Bakken, and Tom Mullen are pictured after receiving the Medtronic Patent of Distinction Award, the $12^{\text {th }}$ award granted in Medtronic's history of more than 65 years recognizing disruptive innovation.

clinical evaluation of Medtronic's noncompetitive atrial pacing feature in the Thera ${ }^{\mathrm{TM}} \mathrm{DR}$ pacemaker (Medtronic); (2) a postatrial refractory period of $600 \mathrm{~ms}$ for rates below $75 \mathrm{bpm}$ and $75 \%$ of the ventricular interval for rates above $75 \mathrm{bpm}$, both of which were somewhat arbitrarily chosen to delineate premature atrial contractions from "physiologic" atrial sensed events originating from the sinus node; (3) a reverse mode switching AA/IR+ to DDD/R in the event of 2:1 block or rhythms having a ratio of $\mathrm{A}: \mathrm{V}$ events below 4:3; (4) a mode switching to DDI/R from either AAI/R+ or DDD/R, in the event of AF; (5) periodic attempts to restore AAI/R+ operation following DDD/R reversion by withholding singular ventricular paced events at geometrically increasing intervals (eg, one minute, two minutes, four minutes, eight minutes-up to 16 hours); and (6) a premature ventricular contraction (PVC) response during AAI/R+ operation that suspends atrial pacing to eliminate potential VT detection interference from postatrial and ventricular cross-blanking following PVCs and PVC runs. Figure 1 demonstrates basic MVPTM operation.

In the end, four engineers can be credited as the inventors of MVPTM ${ }^{29}$ Casavant and Belk were the primary architects, while Tom Mullen, $\mathrm{PhD}$, contributed solutions to several of the pace timing issues necessary to make the final MVPTM design reliable in the general pacing population and was also instrumental in the design, data analysis, and publication of the MVP Gem III DR download study. ${ }^{30}$ The fourth inventor, John Stroebel, a veteran Medtronic system engineer, contributed to the final design of MVPTM and conceived a sophisticated "underthe-hood" method to implement MVPTM as a download algorithm in the Gem III ICD. His contribution expedited the clinical evaluation of the algorithm and hastened commercial approval for MVPTM. The timeline for MVPTM conception to market approval is depicted in Figure 4.

Of course, the complete list of MVP ${ }^{\mathrm{TM}}$ contributors is vast and includes all those who participated in the planning, design, development, and regulatory approval. MVPTM received regulatory approval based on one-week data obtained from 30 patients of Dr. Michael O. Sweeney, an electrophysiologist from Boston's Brigham and Women's Hospital (BWH), and on multicenter data from 206 patients having the MVPTM algorithm temporarily downloaded as "RAMware" into the Marquis DR ICD. ${ }^{31}$ The commercial release occurred in 2004 with the launch of the Medtronic Intrinsic ${ }^{\mathrm{TM}} \mathrm{ICD} .{ }^{32}$ The MVP ${ }^{\mathrm{TM}}$ story would not be complete without also crediting Dr. Sweeney for coincidentally coming to the nearly simultaneous realization that RV overpacing was harmful. Dr. Sweeney's first recognition of the deleterious impact of RV pacing came during analyses of the results from the landmark MOST study, which failed to show a significant benefit of DDD over VVIR pacing, ${ }^{33}$ and his extensive subanalyses showed that ventricular overpacing, either in the DDD or VVIR mode, contributed to incidence rates of HF hospitalization and AF in pacemaker patients. ${ }^{4}$ After joining Medtronic as a consultant on the MVPT technology, his relentless advocacy and teachings solidified his position as a primary advisor and investigator of MVPTM . 
Dr. Sweeney oversaw the first-in-man applications of MVPTM $^{\mathrm{TM}}$ BWH in late 2002 and his established authority as a key opinion leader greatly influenced expedited testing and commercial approval of MVPTM. Dr. Sweeney is primarily responsible for ultimately convincing the worldwide pacing community that MVPTM was a solution to $\mathrm{DDD} / \mathrm{R}$ pacing and that the maintenance of cardiac harmonious activation via its innate "infinite virtual electrode" is highly preferable over optimal AV timing.

\section{Other AAl $\leftrightarrow$ DDD algorithms}

Near the time of MVPTM's approval or soon thereafter, all other cardiac rhythm device companies secured approval for commercial release of more assertive ventricular pace minimization algorithms. AAISafeR ${ }^{\circledast}$ and AAISafeR 2 (ELA/Sorin, Milan, Italy), released internationally in 2003 and 2005, respectively, were the only other pacing modes having $\mathrm{AAI} / \mathrm{R} \leftrightarrow \mathrm{DDD} / \mathrm{R}$ functionality similar to MVPTM at the time. (MVPTM and AAISafeR 2 DDD/ AAI modes were conceived by autonomous inventors from independent companies working in the United States and France, respectively.) Strategies used by other manufacturers included Auto-intrinsic Conduction Search $^{\circledast}$ (AICS) in 2006 (St. Jude Medical), Ventricular Intrinsic Preference ${ }^{\circledR}$ (VIP) in 2007 (St. Jude Medical), AV Search Hysteresis ${ }^{\circledast}$ (AVSH) in 2007 (Guidant), Vp Suppression ${ }^{\circledast}$ and Intrinsic Rhythm Search ${ }^{\circledR}$ (IRSplus) in 2010 (Biotronik, Berlin, Germany), and Rhythm IQ ${ }^{\circledR}$ in 2012 (Boston Scientific, Natick, MA, USA).

\section{MVPтм 2.0}

The second generation of MVPTM was implemented in cardiac rhythm devices released beginning in 2017 with slight modifications, including an optional programmable limit for the longest allowed A-R interval and an enhancement to lessen the duration of long $\mathrm{V}-\mathrm{V}$ intervals and the severity of short-long-short (S-L-S). This second version of MVP ${ }^{\mathrm{TM}}$ employs a dynamic, adjusting $\mathrm{A}-\mathrm{A}$ interval and a programmable maximum $\mathrm{AV}$ interval limit such that switching to DDD/R occurs if two of four Ap-Vs or As-Vs intervals exceed this limit. ${ }^{34,35}$

\section{Final perspectives}

Many agree that the rapid acceptance of MVPTM was largely due to its simplicity in that it more closely mimicked normal activation of the heart and allowed for the management of non-pacemaker-indicated rhythms-including first-degree and second-degree Mobitz I, type I "Wenckebach" heart block. This simplicity was enhanced by its lack of programmable parameters. MVP ${ }^{\mathrm{TM}}$ was introduced as an ON/OFF feature, a characteristic the inventors vehemently defended, thereby avoiding the "feature creep" that often results from the desire to appease all. The naming of this mode is owed to Dr. Sweeney.

In some ways, MVPTM can be viewed as a precursor to future permanent His-bundle pacemaker modalities (eg, sequential A-H pacing systems) given that both favor normal ventricular activation. In fact, it is being employed on occasion for patients with intermittent heart block receiving $\mathrm{A}-\mathrm{H}$ pacing systems by programming short $\mathrm{AV}$ delays consistent with normal A-H intervals.

MVP $^{\mathrm{TM}}$ has seen very high levels of clinical success in prospective, randomized clinical trials. The MVPTM versus VVI 40 pacing trial, performed in an ICD population, similar to the DAVID trial, was stopped for futility as the combined endpoint of worsening HF or all-cause death was equally low in both arms. ${ }^{31}$ The Search AV Extension and Managed Ventricular Pacing for Promoting Atrioventricular Conduction (SAVe PACe) pacemaker trial showed that, in patients paced using a minimal ventricular pacing strategy, the risk of progression to persistent $\mathrm{AF}$ was reduced by $40 \%{ }^{36}$ An ensuing multicenter 1,166-patient pacemaker trial known as Minimize Right Ventricular Pacing to Prevent AF and HF (MINERVA) demonstrated that the combined efficacy of MVPTM when prescribed alone-and particularly when combined with atrial antitachycardia pacing-achieved a significant overall reduction in the progression to permanent or persistent $\mathrm{AF}$ as compared with among DDDR-paced patients. ${ }^{37}$

Although the MVPTM mode significantly reduced ventricular pacing in the majority of patients, including those having a heart block indication, ${ }^{2,38}$ some criticisms of the mode for allowing occasional pauses that were excessively long have arisen. Sweeney et al. somewhat debunked the notion that pauses were more significant than in other modalities such as backup VVI pacing and showed that, although (nonpaced) S-L-S sequences were permitted more frequently by MVPTM, S-L-S sequences terminating with a paced beat were not. ${ }^{39}$

MVPTM has not experienced unconditional patient acceptance. MVPTM has been implicated in VTs in prone patients. ${ }^{40-43}$ However, some patients have reported vague symptoms from pseudo-pacemaker syndrome due to sustained periods of first-degree block with very long $\mathrm{P}-\mathrm{R}$ intervals. Some patients have not tolerated MVPTM due to symptoms attributed to extended pauses following nonconducted atrial events. Still, experience to date has revealed that only a small minority of MVPTM paced patients have been reprogrammed to conventional DDD/R pacing. Overall, MVP 2.0 has addressed concerns.

Despite its shortcomings, MVPTM has been a huge clinical success that resulted from hard work, research, and serendipity. MVP ${ }^{\mathrm{TM}}$ represents a product of collaboration amongst engineers and physicians, an attribute that is shared by so many important innovations in medicine.

\section{Looking to the future}

Importantly, MVPTM is not the optimal solution: clinical equipoise is imposed by the competing goals of optimizing $\mathrm{AV}$ synchrony while maintaining normal ventricular activation, particularly in patients having long $\mathrm{P}-\mathrm{R}$ and 
narrow QRS intervals. In pacemaker-indicated patients, optimizing the AV interval using DDD pacing is only indicated in the event of symptoms due to severe $\mathrm{AV}$ decoupling (ie, pseudo-pacemaker syndrome). ${ }^{44}$ In HF patients, physician sentiment continues to favor AAI/R (ie, MVPTM) and other modes that limit RV pacing. ${ }^{4-47}$ Ultimately, permanent His-bundle and direct conduction-system pacing will provide better solutions.

\section{Acknowledgments}

Key physicians who contributed to the development of MVP ${ }^{\mathrm{TM}}$ include Mark Josephson, Paul Belk's clinical advisor, whose intellect, boundless energy, and unmitigated desire to advance medicine were unmatched, while other influential physicians of note are Drs. Kevin Monahan and Michael Epstein, who are early FAPTT champions, and Dr. Roy John, who provided access for animal experiments at Lahey Clinic in Burlington, MA. The complete list is vast and includes all those who participated in the planning, design, development, and regulatory approval. Most notably, the Medtronic scientists who deserve credit include Toby Markowitz, an established thought leader who had pioneered many pacing innovations, and Todd Sheldon, who designed and supported many clinical trials involving MVPTM and who is largely responsible for the modifications in MVPTM 2.0. Bob Betzold, a systems engineer, contributed a great deal to MVP ${ }^{\mathrm{TM}}$ implementation. Walt Olsen, Medtronic's research director during the development phase, played a critical oversight role. A final thank you goes to Eric G. Singh for conducting a critical review of this paper.

\section{References}

1. Castillo CA, Berkovits BV, Castellanos AJr., Lemberg L, Callard G, Jude JR. Bifocal demand pacing. Chest. 1971;59(4):360-364.

2. Gillis AM, Purerfellner H, Israel CW, et al. Reducing unnecessary right ventricular pacing with the managed ventricular pacing mode in patients with sinus node disease and AV block. Pacing Clin Electrophysiol. 2006;29(7):697-705.

3. Wilkoff BL, Cook JR, Epstein AE, et al. Dual-chamber pacing or ventricular backup pacing in patients with an implantable defibrillator: the Dual Chamber and VVI Implantable Defibrillator (DAVID) Trial. JAMA. 2002;288(24):3115-3123.

4. Sweeney MO, Hellkamp AS, Ellenbogen KA, et al. Adverse effect of ventricular pacing on heart failure and atrial fibrillation among patients with normal baseline QRS duration in a clinical trial of pacemaker therapy for sinus node dysfunction. Circulation. 2003;107(23):2932-2937.

5. Vernooy K, Verbeek XA, Peschar M, Prinzen FW. Relation between abnormal ventricular impulse conduction and heart failure. J Interv Cardiol. 2003;16(6):557-562.

6. Salukhe TV, Francis DP, Sutton R. Comparison of medical therapy, pacing and defibrillation in heart failure (COMPANION) trial terminated early; combined biventricular pacemaker-defibrillators reduce all-cause mortality and hospitalization. Int J Cardiol. 2003;87(2-3):119-120.

7. Linde C, Leclercq C, Rex S, et al. Long-term benefits of biventricular pacing in congestive heart failure: results from the MUltisite STimulation in cardiomyopathy (MUSTIC) study. J Am Coll Cardiol. 2002;40(1):111-118.
8. Casavant D. Facilitated Atrial Pacing Threshold Test. USPTO. Minneapolis, MN: Medtronic, Inc.; 1997.

9. Nielsen JC, Kristensen L, Andersen HR, Mortensen PT, Pedersen OL, Pedersen AK. A randomized comparison of atrial and dual-chamber pacing in 177 consecutive patients with sick sinus syndrome: echocardiographic and clinical outcome. J Am Coll Cardiol. 2003;42(4):614-623.

10. Barold SS. Permanent single chamber atrial pacing is obsolete. Pacing Clin Electrophysiol. 2001;24(3):271-275.

11. Wilkoff BL. Should all patients receive dual chamber pacing ICDs? The rationale for the DAVID trial. Curr Control Trials Cardiovasc Med. 2001;2(5):215-217.

12. Cazeau S, Leclercq C, Lavergne $T$, et al. Effects of multisite biventricular pacing in patients with heart failure and intraventricular conduction delay. $N$ Engl J Med. 2001;344(12):873-880.

13. Duncan A, Wait D, Gibson D, Daubert JC, Trial M. Left ventricular remodelling and haemodynamic effects of multisite biventricular pacing in patients with left ventricular systolic dysfunction and activation disturbances in sinus rhythm: sub-study of the MUSTIC (Multisite Stimulationin Cardiomyopathies) trial. Eur Heart J. 2003;24(5):430-441.

14. Auricchio A, Stellbrink C, Sack S, et al. Long-term clinical effect of hemodynamically optimized cardiac resynchronization therapy in patients with heart failure and ventricular conduction delay. J Am Coll Cardiol. 2002;39(12):2026-2033.

15. Butter C, Auricchio A, Stellbrink C, et al. Effect of resynchronization therapy stimulation site on the systolic function of heart failure patients. Circulation. 2001;104(25):3026-3029.

16. Stellbrink C, Breithardt OA, Franke A, et al. Impact of cardiac resynchronization therapy using hemodynamically optimized pacing on left ventricular remodeling in patients with congestive heart failure and ventricular conduction disturbances. J Am Coll Cardiol. 2001;38(7):1957-1965.

17. Kosowsky BD, Scherlag BJ, Damato AN. Re-evaluation of the atrial contribution to ventricular function: study using His bundle pacing. Am J Cardiol. 1968;21(4):518-524.

18. Deshmukh P, Casavant DA, Romanyshyn M, Anderson K. Permanent, direct His-bundle pacing: a novel approach to cardiac pacing in patients with normal His-Purkinje activation. Circulation. 2000;101(8):869-877.

19. Leclercq C, Gras D, Le Helloco A, Nicol L, Mabo P, Daubert C. Hemodynamic importance of preserving the normal sequence of ventricular activation in permanent cardiac pacing. Am Heart J. 1995;129(6):1133-1141.

20. Lee MA, Dae MW, Langberg JJ, et al. Effects of long-term right ventricular apical pacing on left ventricular perfusion, innervation, function and histology. J Am Coll Cardiol. 1994;24(1):225-232.

21. Brandt J, Anderson H, Fahraeus T, Schuller H. Natural history of sinus node disease treated with atrial pacing in 213 patients: implications for selection of stimulation mode. $J$ Am Coll Cardiol. 1992;20(3):633-639.

22. Rosenqvist M, Brandt J, Schuller H. Long-term pacing in sinus node disease: effects of stimulation mode on cardiovascular morbidity and mortality. Am Heart J. 1988;116(1 Pt 1):16-22.

23. Rosenqvist $M$, Brandt $J$, Schuller $H$. Atrial versus ventricular pacing in sinus node disease: a treatment comparison study. Am Heart J. 1986;111(2):292-297.

24. Saxon LA, Stevenson WG, Middlekauff HR, Stevenson LW. Increased risk of progressive hemodynamic deterioration in advanced heart failure patients requiring permanent pacemakers. Am Heart J. 1993;125(5 Pt 1):1306-1310.

25. Belk P, Casavant D, Smith T, et al. Does ventricular pacing predispose to ventricular tachycardia? PACE. 2000;23. 
26. Silverman R, Casavant D, Loucks S, Lundstrom R, Lynn T. Atrioventricular interval search: a dual chamber pacemaker feature to promote intrinsic A-V conduction. Pacing Clin Electrophysiol. 1999;22(Pt II):873.

27. Stierle U, Kruger D, Vincent AM, et al. An optimized AV delay algorithm for patients with intermittent atrioventricular conduction. Pacing Clin Electrophysiol. 1998;21(5):1035-1043.

28. Mayumi H, Kohno H, Yasui H, Kawachi Y, Tokunaga K. Use of automatic mode change between DDD and AAI to facilitate native atrioventricular conduction in patients with sick sinus syndrome or transient atrioventricular block. Pacing Clin Electrophysiol. 1996;19(11 Pt 2):1740-1747.

29. Casavant D, Belk PA, Mullen TJ, Stroebel JC. Preferred $\mathrm{ADI} / \mathrm{R}$ : a permanent pacing mode to eliminate ventricular pacing while maintaining backup support. In: Office UPaT, ed. USPTO. Minneapolis, MN: Medtronic, Inc.; 2004: 16.

30. Sweeney MO, Shea JB, Fox V, et al. Randomized pilot study of a new atrial-based minimal ventricular pacing mode in dual-chamber implantable cardioverter-defibrillators. Heart Rhythm. 2004;1:160-167.

31. Sweeney MO, Ellenbogen KA, Casavant D, et al. Multicenter, prospective, randomized safety and efficacy study of a new atrial-based managed ventricular pacing mode (MVP) in dual chamber ICDs. J Cardiovasc Electrophysiol. 2005;16(8):811-817.

32. United States Food and Drug Administration. Medtronic intrinsic models 7287 and 7288 ICD systems. Available at: https:/ / fda.report/PMA/P980016S043. Accessed November $1,2020$.

33. Lamas GA, Lee KL, Sweeney MO, et al. Ventricular pacing or dual-chamber pacing for sinus-node dysfunction. $N$ Engl J Med. 2002;346(24):1854-1862.

34. Medtronic, Inc. Medtronic Azure MRI Surescan/Astra MRI Surescan Reference Manual. Minneapolis, MN: Medtronic, Inc; 2017. Available at: manuals.medtronic.com.

35. Ventricular pause and second MVP version. Cardiocases. Available at: https://www.cardiocases.com/en/pacingdefibrillation/traces/pm/medtronic/ventricular-pause-andsecond-mvp-version. Accessed November 1, 2020.

36. Sweeney MO, Bank AJ, Nsah E, et al. Minimizing ventricular pacing to reduce atrial fibrillation in sinus-node disease. N Engl J Med. 2007;357(10):1000-1008.

37. Padeletti L, Purerfellner H, Mont L, et al. New-generation atrial antitachycardia pacing (Reactive ATP) is associated with reduced risk of persistent or permanent atrial fibrillation in patients with bradycardia: results from the MINERVA randomized multicenter international trial. Heart Rhythm. 2015;12(8):1717-1725.

38. Milasinovic G, Tscheliessnigg K, Boehmer A, et al. Percent ventricular pacing with managed ventricular pacing mode in standard pacemaker population. Europace. 2008;10(2): 151-155.

39. Sweeney MO, Ruetz LL, Belk P, Mullen TJ, Johnson JW, Sheldon T. Bradycardia pacing-induced short-long-short sequences at the onset of ventricular tachyarrhythmias: a possible mechanism of proarrhythmia? J Am Coll Cardiol. 2007;50(7):614-622.

40. Alnsasra H, Konstantino Y, Bereza S, Haim M. Successful treatment of ventricular fibrillation storm triggered by short-long-short sequence; time to avoid managed ventricular pacing. J Electrocardiol. 2017;50(6):941-943.

41. Mansour F, Khairy P. Electrical storm due to managed ventricular pacing. Heart Rhythm. 2012;9(5):842-843.

42. Sekita G, Hayashi H, Nakazato Y, Daida H. Ventricular fibrillation induced by short-long-short sequence during managed ventricular pacing. J Cardiovasc Electrophysiol. 2011;22(10):1181.

43. Vavasis C, Slotwiner DJ, Goldner BG, Cheung JW. Frequent recurrent polymorphic ventricular tachycardia during sleep due to managed ventricular pacing. Pacing Clin Electrophysiol. 2010;33(5):641-644.

44. Epstein AE, DiMarco JP, Ellenbogen KA, et al. ACC/AHA/ HRS 2008 guidelines for device-based therapy of cardiac rhythm abnormalities: a report of the American College of Cardiology/American Heart Association Task Force on Practice Guidelines (Writing Committee to Revise the ACC/ AHA/NASPE 2002 Guideline Update for Implantation of Cardiac Pacemakers and Antiarrhythmia Devices): developed in collaboration with the American Association for Thoracic Surgery and Society of Thoracic Surgeons. Circulation. 2008;117(21):e350-e408.

45. Steinberg JS, Fischer A, Wang $\mathrm{P}$, et al. The clinical implications of cumulative right ventricular pacing in the multicenter automatic defibrillator trial II. I Cardiovasc Electrophysiol. 2005;16(4):359-365.

46. Sharma AD, Rizo-Patron C, Hallstrom AP, et al. Percent right ventricular pacing predicts outcomes in the DAVID trial. Heart Rhythm. 2005;2(8):830-834.

47. Barsheshet A, Moss AJ, McNitt S, et al. Long-term implications of cumulative right ventricular pacing among patients with an implantable cardioverter-defibrillator. Heart Rhythm. 2011;8(2):212-218. 